University of Louisville

ThinkIR: The University of Louisville's Institutional Repository

Electronic Theses and Dissertations

$12-2003$

\title{
A Markov model of secondary prevention of osteoportic hip fractures.
}

Stephanie Tapp

University of Louisville

Follow this and additional works at: https://ir.library.louisville.edu/etd

\section{Recommended Citation}

Tapp, Stephanie, "A Markov model of secondary prevention of osteoportic hip fractures." (2003). Electronic Theses and Dissertations. Paper 1419.

https://doi.org/10.18297/etd/1419

This Master's Thesis is brought to you for free and open access by ThinkIR: The University of Louisville's Institutional Repository. It has been accepted for inclusion in Electronic Theses and Dissertations by an authorized administrator of ThinkIR: The University of Louisville's Institutional Repository. This title appears here courtesy of the author, who has retained all other copyrights. For more information, please contact thinkir@louisville.edu. 


\title{
A MARKOV MODEL OF SECONDARY PREVENTION OF OSTEOPOROTIC HIP FRACTURES
}

\author{
By \\ Stephanie Tapp \\ B.A., University of Louisville, 1997
}

\begin{abstract}
A Thesis
Submitted to the Faculty of the Graduate School of the University of Louisville in Partial Fulfillment of the Requirements for the Degree of
\end{abstract}

Master of Science in Public Health

Department of Bioinformatics and Biostatistics University of Louisville

Louisville, Kentucky

December 2003 



\title{
A MARKOV MODEL OF SECONDARY PREVENTION OF OSTEOPOROTIC HIP FRACTURES
}

\author{
By \\ Stephanie Tapp \\ B.A., University of Louisville, 1997
}

A Thesis Approved On

Date

by the following Thesis Committee:

Thesis Director 


\section{ACKNOWLEDGEMENTS}

I would like to thank my thesis advisor Steve McCabe, MD. He was instrumental in taking this thesis from an abstract idea to a workable project. I am especially grateful to my committee members, Dr. Gerald Evans and Dr. Tonya Smoot. Not only did they graciously accept the responsibility of serving on my committee when deadlines were closing in, but their comments and suggestions were invaluable.

I am indebted to my family who has supported me throughout this process. My mother, Melanie, my brothers Benjaman and Andrew and my sister Morgan have all been instrumental in helping me find time when there was none.

I would like to thank my husband, Jonathan for his love and support. He has encouraged me to persevere through adversity and to resist my tendencies to procrastinate.

Finally, I'd like to dedicate this thesis to my new baby, Lydia, born June 30, 2003. It is entirely her patience with me that has allowed a single word of this thesis to be written. 


\begin{abstract}
A MARKOV MODEL OF SECONDARY PREVENTION OF OSTEOPOROTIC HIP FRACTURES
\end{abstract}

Stephanie Tapp

December 18, 2003

Low-trauma fractures of older women are a major public health burden. Fractures of the hip and spine are some of the primary causes of chronic pain, functional impairment, and disability among the elderly [1].

The underlying cause of these fractures is osteoporosis. Although the disease is common, only a small proportion $(15 \%-20 \%)$ of women at risk currently receive preventative treatment [2].

We have focussed our attention to white postmenopausal women who have sustained a fracture of the distal radius. We developed a Markov model using probabilities obtained from recent literature in order to evaluated the effects of three hypothetical interventions targeted towards women after presenting with a wrist fracture. We analyzed this model using Monte Carlo simulations.

Our results indicate that if an intervention can be developed for this population, then mean survival can be increased and the number of subsequent hip fractures can be decreased. 


\section{TABLE OF CONTENTS}

Page

ACKNOWLEDGEMENTS

ABSTRACT

iv

LIST OF TABLES

vii

LIST OF FIGURES

viii

\section{CHAPTER}

$\begin{array}{llr}\text { I INTRODUCTION } & 1\end{array}$

A Osteoporosis ........................... 1

1 Definition ................... 1

2 Incidence and Prevalence . . . . . . . . . . . 3

3 Risk Factors for Bone Loss . . . . . . . . . . . . . . . 4

B Osteoporotic Fractures . . . . . . . . . . . . . . . 4

$1 \quad$ Fragility Fractures . . . . . . . . . . . . . 4

2 Wrist Fractures . . . . . . . . . . . . . . 6

3 Vertebral Fractures ................ 7

$4 \quad$ Hip Fractures . . . . . . . . . . . . . . . . . . . 8

C Identification of Those At Risk . . . . . . . . . . . . 10

$1 \quad$ Low Bone Mineral Density . . . . . . . . . . . . . . 10

2 Previous Fracture ................. 13

D Treatment/Fracture Prevention . . . . . . . . . . . . 14 
1 Drug Therapy . . . . . . . . . . . . . . 15

2 Hip Protectors . . . . . . . . . . . . . 15

E The Current Research . . . . . . . . . . . . . . 16

$\begin{array}{lr}\text { II MODEL OF THE PROBLEM } & 17\end{array}$

A Markov Model ... . . . . . . . . . . . . 17

B The Markov-Cycle Tree . . . . . . . . . . . . . . . . 19

1 Transition Probabilities . . . . . . . . . . . 26

2 Model Variables ................ 26

$\begin{array}{ll}\text { III MONTE CARLO SIMULATION } & 31\end{array}$

A Analysis ......................... 31

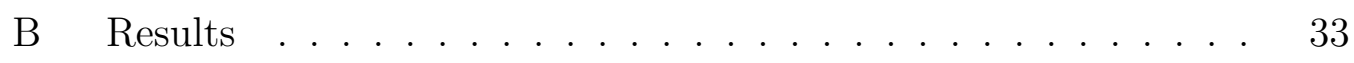

C Discussion .......................... 37

D Suggestions For Further Research . . . . . . . . . . . . . . . . 37

$\begin{array}{lll}\text { IV CONCLUSION } & 40\end{array}$

$\begin{array}{ll}\text { REFERENCES } & 41\end{array}$

$\begin{array}{ll}\text { CURRICULUM VITAE } & 47\end{array}$ 


\section{LIST OF TABLES}

\section{TABLE}

Page

1 Diagnostic Categories for Osteoporosis . . . . . . . . . . . . . . 3

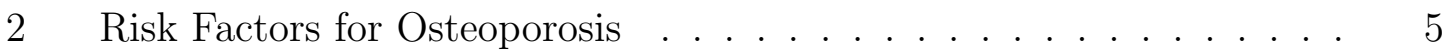

3 List of Tracker Variables Used in the Model . . . . . . . . . . . . . . 27

$4 \quad$ All Cause Mortality . . . . . . . . . . . . . . . . . . 27

5 Risk of Mortality in the General Population . . . . . . . . . . . . 28

6 Model Variable tProbHipFracture . . . . . . . . . . . . . . . . . 29

$7 \quad$ Model Variable tProbWristFracture . . . . . . . . . . . . . . . . . . . 30

8 Model Variable tMortPostHip . . . . . . . . . . . . . . . . . . 30

9 Values Used for the Variable $n$ in the Model . . . . . . . . . . . . . . 33

10 Survival Table . . . . . . . . . . . . . . . . . . . . . . . 34

11 Number of Patients that Experienced Zero Fractures for Each Inter-

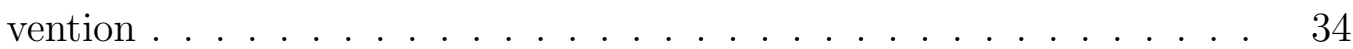

12 Number of Patients that Experienced Two Fractures for Each Inter-

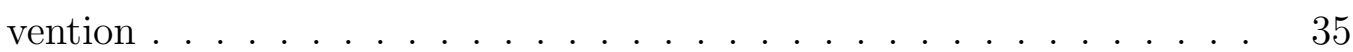

13 Distribution of Age at Time of First Hip Fracture . . . . . . . . . . 35

14 Distribution of Age at Time of First Hip Fracture . . . . . . . . . . . 36

15 Cost-Effective Interventions _ . . . . . . . . . . . . . . . . . . 38 


\section{LIST OF FIGURES}

$\begin{array}{ll}\text { FIGURE } & \text { Page }\end{array}$

$1 \quad$ Illustration of Osteoporotic Bone . . . . . . . . . . . . . . . . 2

2 Illustration of Colles Fracture . . . . . . . . . . . . . . . . 6

$3 \quad$ Illustration of Fractured Hip . . . . . . . . . . . . . . . . . 7

$4 \quad$ State-Transition Diagram _. . . . . . . . . . . . . . 18

$5 \quad$ Full Tree ........................... 21

6 Annotated Tree . . . . . . . . . . . . . . . . . 22

7 Annotated Tree (Continued) . . . . . . . . . . . . . 23

$8 \quad$ Markov State Information . . . . . . . . . . . . . . . . 25

$9 \quad$ Portion of Tree Changed for Intervention Effectivness . . . . . . . . . 32 


\section{CHAPTER I}

\section{INTRODUCTION}

During the first 25 to 30 years of a woman's life, new bone is made faster than existing bone is broken down. During the next 10 to 20 years, bone is broken down at about the same rate as bone is made. During menopause, inadequate estrogen causes accelerated bone loss. In women between the ages of 45 and 55 (soon after menopause), bone begins to break down faster than new bone is made. Bone loss in women varies but usually occurs at a faster rate (up to $6 \%$ per year) during the first few years after menopause, then tapers to $2 \%$ per year thereafter. Without effective prevention, a woman can lose 20\%-30\% of her bone mass during the first 10 years of menopause.

\section{A Osteoporosis}

\section{Definition}

In 1990, the consensus development panel defined osteoporosis as a "disease characterized by low bone mass and microarchitectural deterioration of bone tissue, leading to enhanced bone fragility and a consequent increase in fracture risk [2]." The World Health Organization categorizes osteoporosis based on patients' increased susceptibility to fractures of the hip, spine, and wrist [4].

Although accurate, these definitions are difficult to apply in clinical practice. 


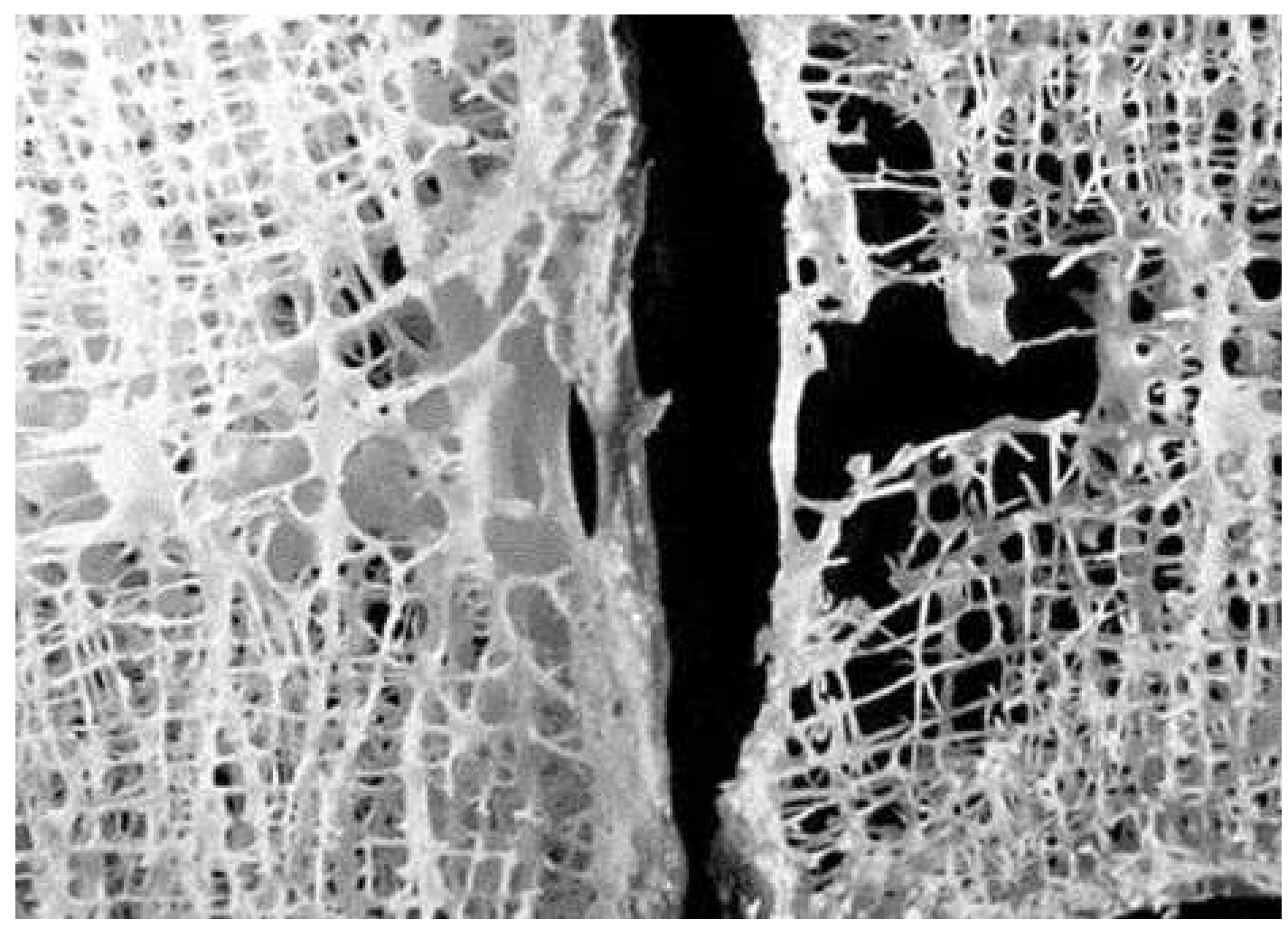

Figure 1. Here, a portion of a bone showing signs of osteoporosis (right) is contrasted with a portion of a healthy bone (left). Bones weakened by osteoporosis are much more vulnerable to fracture than are denser healthy bones [3].

Instead, physicians usually use the occurrence of a non-traumatic fracture to consider a diagnosis of osteoporosis. Unfortunately, the presence of fractures usually implies advanced disease [4].

The risk of fracture is inversely proportional to bone mineral density. Since fracture risk is a continuum, it is misleading to say that osteoporosis is "present" or "absent" [2]. However, for practical purposes, researchers have defined a cutoff value for osteoporosis as a bone mineral density that is 2.5 standard deviations less than the average value for young adults. This is illustrated in Table 1. According to this cutoff value, approximately $30 \%$ of postmenopausal women at the highest risk of 


\section{TABLE 1}

Diagnostic categories for osteoporosis in postmenopausal women according to DXA measurements based on World Health Organization Criteria [5, 6].

\begin{tabular}{ll}
\hline Category & Definition by bone density \\
\hline Normal & A value for BMD that is not more than 1 SD below the young \\
adult mean value. & A value for BMD that lies between 1 and 2 SD below the \\
Osteopenia & young adult mean value. \\
Osteoporosis & $\begin{array}{l}\text { A value for BMD that is more than } 2.5 \mathrm{SD} \text { below the young } \\
\text { adult mean value. }\end{array}$ \\
Severe Osteoporosis & $\begin{array}{l}\text { A value for BMD more than } 2.5 \mathrm{SD} \text { or below the young adult } \\
\text { mean in the presence of one or more fragility fractures. }\end{array}$ \\
\hline
\end{tabular}

fracture are identified [1].

\section{Incidence and Prevalence}

The prevalence of osteoporosis is difficult to gauge, since it can be defined by the number of fractures incurred or in terms of bone mineral density in relation to the average young adult population [7]. Regardless, osteoporosis is the most common disorder of the bone [8], and one of the most prevalent chronic health conditions among the elderly [2].

Prior to menopause, few women have osteoporosis, but the incidence and prevalence of the disease increases with age due to progressive loss of bone after menopause $[2,5]$. While approximately $15 \%$ of young adults have osteopenia, only about $0.6 \%$ have osteoporosis (as defined in Table 1). By age 60-70 years, for every nine women: five have osteopenia, three have osteoporosis, and only one has normal bone mineral density. By age 80 years, at least $70 \%$ of women have osteoporosis [2]. 
Based on these figures, about $54 \%$ of postmenopausal white women in the United states have osteopenia and between $25 \%$ and $30 \%$ have osteoporosis $[2,4,9]$. Estimates predict that more than half of the women in the United States will experience an osteoporotic fracture during their lifetime [2].

Osteoporosis is recognized as a significant public health problem because of the increased morbidity and mortality associated with its complications. Untreated osteoporosis can lead to bone fractures that may result in permanent disability. In fact, fractures at most sites in the elderly can be traced to osteoporosis [10].

\section{Risk Factors for Bone Loss}

Risk factors for osteoporosis and osteoporotic fractures have been determined and are used to identify the need for further evaluation. In women, the loss of estrogen at menopause is the major change leading to bone loss [8], but other risk factors such as advanced age, reduced physical activity, smoking and alcohol abuse contribute additively to bone loss [11]. Risk factors can be categorized as modifiable and non-modifiable as represented in Table 2.

\section{B Osteoporotic Fractures}

\section{Fragility Fractures}

A fragility fracture is a fracture that is due to minor trauma. Most fragility fractures in the elderly are due to the type of injury that would not cause fractures among normal healthy adults. In fact, as many as $90 \%$ of hip and wrist fractures among the elderly in the United States are associated with mild trauma, such as a fall from standing height or lower [2]. Unfortunately, just as the risk of developing 
TABLE 2

Risk factors for osteoporosis [5].

\begin{tabular}{ll}
\hline Modifiable & Non-modifiable \\
\hline Inadequate exercise & Age \\
Inadequate nutrition & Gender \\
Calcium & Race \\
$\quad$ Vitamin D & Early Menopause \\
Smoking & Family history of fractures \\
Alcohol Abuse & \\
Medicaitons & \\
$\quad$ Glucocorticoids & \\
Benzodiazepines & \\
Anticonvulsants & \\
Thyroid Hornones & \\
\hline
\end{tabular}

osteoporosis increases in the elderly, so does the propensity to fall [12].

Fragility fractures are considered the "hallmark" sign of osteoporosis. Other diseases exist such as bone tumors or bone marrow abnormalities that can lead to bone deterioration, but osteoporosis is the most common cause of brittle bones .

Since osteoporosis is asymptomatic, most patients are not diagnosed until a fracture occurs. The three most common osteoporotic fracture sites are the spine, wrist, and hip. A white postmenopausal woman's lifetime risk of having a one of these fractures is $40-50 \%[2,11,13,14,15,16]$. This risk is expected to approach $75 \%$ in the future [17]. Adults who have sustained one fracture are more likely to have another fracture of a different type [18]. By age 90, 33\% of women will have sustained a hip fracture [19]. A consequence of osteoporotic fractures is a reduction in the quality of life. Anxiety, depression and social loss have all been linked to osteoporosis [11]. 


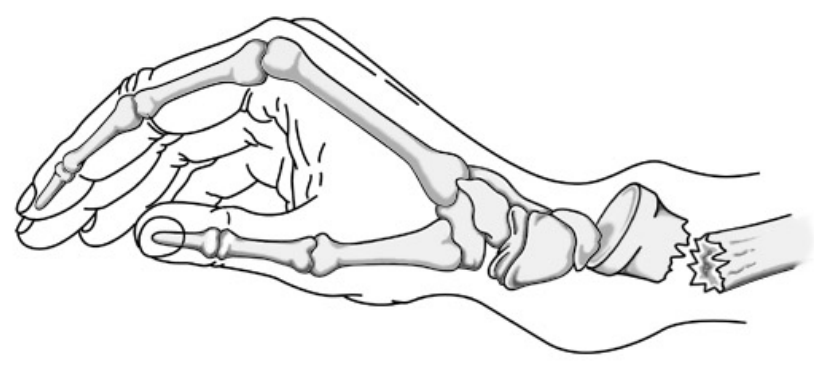

Figure 2. Illustration of radial (Colles) fracture.

\section{Wrist Fractures}

About one-third of all women aged 65 and older fall each year, but only $1 \%$ to $2 \%$ of these women break their wrists [20]. Even so, fracture of the distal radius is the most common breakage in peri-menopausal women. Fifteen to sixteen percent of white women will fracture their wrist after age 50 [18, 20, 21, 22]. Among women in the United States, the incidence of wrist fracture increases rapidly around the time of menopause, then plateaus after age 60 years [2].

Rozental et. al. studied the effect of distal radius fracture on mortality. They concluded that, "Mortality rates after distal radius fractures in our patient cohort were significantly higher than those of the standard US elderly population. The estimated survival in our cohort was $14 \%$ less than expected for elderly US residents from all causes of death [23]." The increase in mortality may be associated with comorbid conditions or with the radial fracture's limiting mobility and independence, which possibly increased the probability of death [23]. 


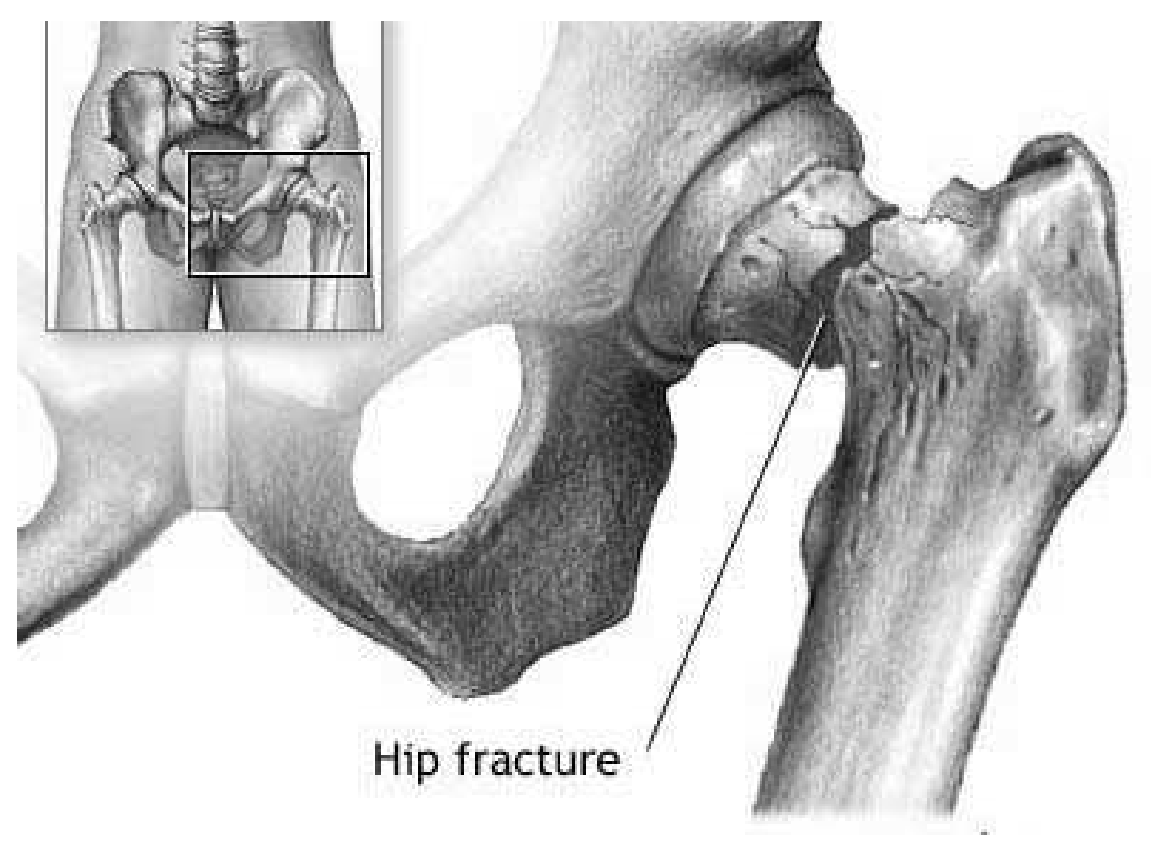

Figure 3. [24]

Radial fractures are the least morbid of osteoporotic fractures. By three years after a wrist fracture, $75 \%$ of patients regain almost full function, with $25 \%$ of patients experiencing variable loss of wrist strength [11].

\section{$3 \quad$ Vertebral Fractures}

Although vertebral fractures are the most common fractures that can be directly attributed to osteoporosis, less is known about their epidemiology because approximately two thirds are asymptomatic and go undetected $[5,16]$. It is estimated that the lifetime risk for a clinically evident vertebral fracture is approximately $16 \%$ in white women [4]. 


\section{Hip Fractures}

By far the most morbid osteoporotic fractures are those involving the hip. Consequently, one of the primary aims of public health measures targeted towards the elderly is hip fracture prevention. From an economic viewpoint, prevention of these fractures is important, because most patients require inpatient surgical treatment and many subsequently need increased costly nursing-home care [25]. In fact, the total 1995 health expenditures for osteoporotic fractures amounted to $1.5 \%$ of National Personal Health Care Expenditures and 2.4\% of National Hospital Care Expenditures. Most of this cost is directly attributable to hip fractures [10].

More than $90 \%$ of hip fractures are associated with osteoporosis [15]. Most mortality associated with osteoporosis is related to hip fractures [2]. One year hip fracture mortality rates of up to $36 \%[25,26]$, have made hip fractures solely responsible for launching osteoporosis into the category of life-threatening disease [4]. As the worlds population ages, hip fractures become more frequent [8].

The incidence of hip fractures rises exponentially with increasing age after about 50 years. The incidence rate among women in the United States ranges form about 2 per 1000 patient-years at age 65 years to a peak of about 30 per 1000 patient-years after age 85 years $[2,5]$. For white women aged 50 years or older, the lifetime risk of hip fracture is approximately $17 \%$, and estimates are that $33 \%$ of women will sustain at least one hip fracture by the age of 90 [4].

The duration of excess mortality attributable to hip fracture has not yet been definitively established. According to Richmond, et. al., the greatest mortality risk is in the first six months of fracture with the risk approaching expected mortality after 6 months [26]. Ross, et. al. suggests that most of the increased mortality occurs during the initial 6 to 12 months after the fracture[2]. But, according to 
Srivastava, et. al. it might take as long as 1 to 2 years for mortality rates return to normal for the hip fracture population [5].

Theodorou et. al. give the mortality rate after hip fractures treated operatively as $5 \%$ to $25 \%$ within the first 3 months [4]. Overall, the fatality rate at one year post-fracture is between $21 \%$ and $24 \%[4,10,11,15]$. In a study by Mellinger, et. al., life expectancy one year after surgery to repair a hip fracture was 7 years, as opposed to 16-20 years for the average person [27].

Hip fractures are arguably the most serious outcome of osteoporosis and are associated with substantial long-term difficulties [8]. Compared with other osteoporotic fractures, fractures of the hip incur the greatest morbidity and direct medical costs for health services [10]. The consequences of hip fractures include hospitalization, lengthy stays in nursing homes and rehabilitation centers, pain, physical impairment, loss of functional abilities, and deterioration in emotional health and social activities [2].

At 1 year after hip fracture, $40 \%$ of patients are still unable to walk independently, 60\% are unable to perform an essential activity of daily living (e.g., dressing, bathing) without assistance, and $80 \%$ are unable to perform an instrumental activity of daily living (e.g., shopping, driving) [5, 11]. In fact, only $16 \%$ of patients who sustain hip fractures regain their functional mobility one year after surgery [27].

After hip fracture, only $50 \%$ of patients return to their pre-fracture health state [4]. Almost 25\% of formerly independent people become at least partially dependent [5], with more than half of hip fracture survivors never regaining their pre-fracture level of walking [25].

Almost half of the patients in a study by Magaziner et. al. were discharged 
to an institution and more than one third were re-hospitalized during the year following their hip fracture [28]. In 1990, the proportion of US hip fracture patients who were discharged from hospital to nursing homes varied from $14 \%$ for those aged 50 to 55 years up to $55 \%$ for those aged 90 years [5]. Admittance to an institution can be devastating for the patient. In a time trade-off study, Salkeld et al. reported that a great majority of elderly women would rather die than be admitted to a nursing home following hip fracture [29].

\section{Identification of Those At Risk}

Robinson, et. al. suggest that if strategies aimed at preventing hip fracture are to be productive, then they should be targeted at subgroups that are at an increased risk of fracture rather than the entire osteoporosis population [25]. To identify patients at high risk of hip fracture, it is necessary to know which risk factors are important and the magnitude of the fracture risk [30].

Currently, low bone mineral density (BMD) and past or current history of fracture are considered the strongest predictors of future osteoporotic fractures among elderly women $[2,11]$.

\section{Low Bone Mineral Density}

Low bone mineral density is the major risk factor for osteoporosis and the strongest predictor of fracture risk. For every standard deviation below the young adult mean that a BMD score falls, the risk for a fracture increases 2 to 3 times [4]. Therefore, it has been suggested that measurements of bone mass should be a precursor to initiating medical treatment of osteoporosis [9], and some experts suggest that all women over the age of 65 years should have a bone density test [31]. 
Several different techniques can be used to measure BMD.

\section{Dual energy X-ray absorptiometry (DEXA):}

DEXA uses two different X-ray beams. The amounts of each X-ray beam that is blocked by bone and soft tissue are compared to estimate the bone density. DEXA is the most accurate method for measuring BMD. It is fast and uses very low doses of radiation. DEXA measures BMD on bones of the spine and hip. Under good conditions, DEXA can measure as little as $2 \%$ of bone loss per year.

\section{Peripheral dual energy X-ray absorptiometry (P-DEXA):}

P-DEXA is a modification of the DEXA technique. It measures bone density in outlying (peripheral) areas of the body, such as the wrist. P-DEXA machines are portable units that can be used in a doctor's office. P-DEXA also uses very low doses of radiation, but the results are usually obtained faster than conventional DEXA measurements. The disadvantages of P-DEXA include an inability to measure density of the bones (in the hip and spine) most likely to fracture because of osteoporosis and its limited usefulness (compared to DEXA) for monitoring the effect of medication used to treat osteoporosis.

\section{Dual photon absorptiometry (DPA):}

DPA uses a radioactive substance (gadolinium) to produce radiation. It can measure the density of bones in thicker parts of the body (such as the hip and spine). DPA has a slower scan time than the other methods; however, like other BMD techniques, DPA uses very low doses of radiation.

\section{Ultrasound:}


Ultrasound is generally used as an initial screening test. If results from an ultrasound test indicate that bone density is low, DEXA is recommended to confirm the results. Ultrasound uses sound waves to determine BMD, usually in the heel. Some machines pass the sound waves through air and some pass them through water. Ultrasound is rapid, painless, and does not use potentially harmful radiation (like X-rays). One disadvantage of ultrasound is its inability to measure density of the bones most likely to fracture (the hip and spine) because of osteoporosis. Also, ultrasound has limited usefulness (compared to DEXA) for monitoring and comparing the effect of medications used to treat osteoporosis.

\section{Quantitative computed tomography (QCT):}

Quantitative computed tomography (QCT) is a type of CT scan that measures the density of a bone in the spine). A form of QCT called peripheral QCT (pQCT) measures the density of bones in peripheral areas of the body, such as the wrist. Because it is expensive and results in a radiation exposure that is 20 to 200 times greater than the other techniques, and because it is less accurate than DEXA, P-DEXA, or DPA, quantitative computed tomography is not usually recommended.

The most established and accessible techniques for assessing low BMD are dual energy X-ray absorptiometry and quantitative computed tomography [9], with dual energy X-ray absorptiometry of the hip considered the "gold standard" for bone mineral density measurement [32]. DEXA is approved by the Food and Drug Administration, and is precise, noninvasive, and takes only 10 minutes to administer [5]. Unfortunately, central DEXA equipment is large, expensive, and not widely 
available. Insurance companies do not consistently cover DEXA testing costs, especially in women younger than 65 years $[9,32]$.

\section{Previous Fracture}

Patients who sustain a fracture of the distal forearm show some similarity regarding risk factors to those who have hip fractures [33]. The incidence of radial fractures rises sharply at around age 55, while the incidence for hip fractures does so at age 70 [34]. Furthermore, the incidence of wrist fracture plateaus in older women, but the incidence of hip fractures increases exponentially to the end of life [17]. This 15 year latent period provides the opportunity to identify individuals at risk well before fracture occurs and to initiate interventions to prevent further bone loss and fracture $[17,33]$.

Several studies have demonstrated an association between a history of low-impact fractures and a subsequent fracture [12, 25, 33, 35]. Gunnes, et al, found that a previous fracture can predict the risk of a subsequent fracture of the hip and spine, and this risk is independent of age [36]. Patients with a prior fracture are two to five times more likely to have future fractures than are persons without fractures $[11,37]$

Mallmin, et. al. suggest that all patients with a fracture of the distal forearm should be considered as potential candidates for prophylactic measures in order to prevent further bone loss and fractures [33], but active intervention to treat osteoporosis after a first fracture in an effort to prevent subsequent fractures is not routine current practice. In a recent retrospective study of over 1000 postmenopausal women who had sustained a wrist fracture, only $24 \%$ underwent

either diagnostic evaluation by the clinician or treatment for osteoporosis [6]. In a 
study by Cuddihy, et. al., it was found that the occurrence of a distal forearm fracture did not appear to be routinely recognized by physicians or patients as a manifestation of osteoporosis, and therefore was not a trigger for an osteoporosis workup [38]. Similarly, Siris, et. al. found that only about 1 in 5 patients who had been seen with a minimal trauma fracture of the hip, wrist, or spine had received treatment for osteoporosis within the next year [32].

\section{Treatment/Fracture Prevention}

Certain medicines that may slow or stop bone loss, increase bone density, and help prevent bone fractures are currently approved by the FDA for treatment of osteoporosis, but treatment cannot eliminate the disease.

The increasing number of therapeutic options for fracture prevention require targeting towards high-risk groups if they are to be cost-effective [30]. Where health-service resources are limited, applying secondary prevention to high-risk groups may be more feasible economically than treating a less narrowly defined population [25].

Preventive strategies aim to reduce the risk of fracture either by focusing on factors that contribute to deterioration of BMD or by introducing measures that increase peak bone mass. However, the lag time between introducing these strategies and seeing the effects is approximately 30 years [7].

A review of the treatment of osteoporosis indicates that prevention is the best solution. Maximization of peak bone mass and reduction of postmenopausal and age-associated bone loss are both crucial. The primary goal in the treatment of osteoporosis is to prevent bone loss beyond the fracture threshold [39].

The National Osteoporosis Foundation recommends treatment to reduce 
fracture risk for all postmenopausal women who present with vertebral or hip fracture, women who have BMD T-scores below -2 and women who have T-scores below 1.5 as well as additional risk factors, especially prior fracture [11].

\section{Drug Therapy}

Patients with the lowest BMD values and a history of prior fractures (i.e. those at the highest risk for re-fracture), are most responsive to current US Food and Drug Administration approved therapies [35]. Several therapeutic agents that decrease fracture risk and increase BMD are available. The U.S. FDA has approved five anti-reabsorption agents: estrogen, calcitonin, and alendronate, risedronate and raloxifene. These drugs act to increase bone mineral density by slowing bone resorption and allowing more balanced bone turnover [17].

There is a strong expression of concern regarding the cost of medication to treat osteoporosis, but studies have shown that drugs can reduce both vertebral and hip fractures by $30 \%$ to $60 \%[35,37]$.

\section{Hip Protectors}

Researchers have been investigating the use of specially designed hip protectors for use with patients that fall into the highest risk for hip fracture. Kannus et. al. found that by wearing a protector at the time of the fall, the risk of fracture can be decreased by more than $80 \%$ [40]. One weakness of this strategy is that patients must be willing to wear the protectors. In the Kannus study, $31 \%$ of the eligible subjects refused to wear the protectors [40]. 


\section{E The Current Research}

The current research looks at patients who have sustained a prior fracture of the distal radius as a target group for osteoporosis treatment and hip fracture prevention. A Markov model has been developed using probabilities obtained from recent literature.

We analyzed our Markov model using Monte Carlo simulations. We have computed the increase in survival and number of fractures avoided based on hypothetical interventions. We began by assuming that a wrist fracture imparts a 2-fold increase in the probability of sustaining a subsequent hip fracture. We changed our model in order to calculate the effect of 3 hypothetical interventions that could be used for every patient that presents with a wrist fracture. These interventions are categorized by the amount they reduce the excess fracture risk. 


\section{CHAPTER II}

\section{MODEL OF THE PROBLEM}

As was discussed in the previous chapter, a fracture of the distal radius is a risk factor for a subsequent hip fracture. This led us to ask the following: "If every woman who presents with a distal radius fracture is treated for osteoporosis, how many hip fractures can we hope to prevent, and how much potential life can be gained?"

We chose to model postmenopausal white women because they represent the group at highest risk for osteoporosis, and because the majority of the literature has focussed on this group.

\section{A Markov Model}

For any given woman, it is uncertain whether she will experience a wrist fracture or hip fracture during her lifetime. In addition, if such a fracture is to occur, it is impossible to predict when or how often. Since the risk is ongoing over time, we decided to analyze the problem using a Markov model. The events of importance are incidences of hip and wrist fractures as well as death from all causes and, specifically, death from hip fractures.

A Markov model assumes that the patient is always in one of a finite number of health states referred to as Markov states. In our model, the Markov states are Well, Hip Fracture, Death From All causes, and Death From Hip Fracture. Each 


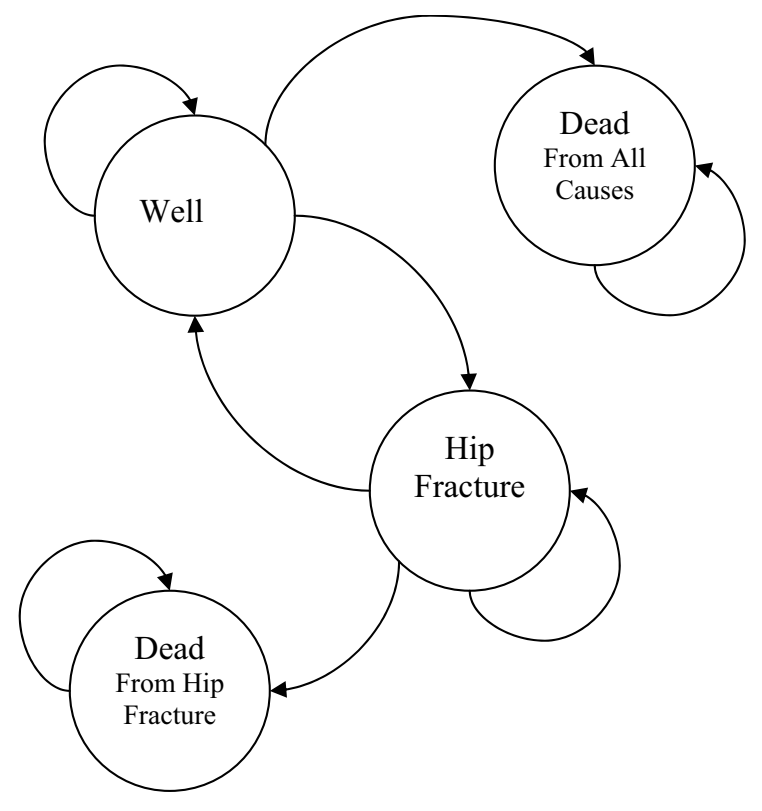

Figure 4. Markov-state diagram. Each circle represents a Markov state. Arrows indicate allowed transitions.

event is modelled as a transition from one state to another.

The time horizon of the analysis was approximately 60 years. This was broken down into equal increments of time called Markov cycles. We chose a cycle length of six months because the literature suggests that the major events that trigger mortality after a hip fracture occur at 6 month intervals post-fracture. During a cycle, a patient may make a transition from one state to another.

In order to develop and analyze our model, we used the software package DATA 4.0 (TreeAge software, Williamstown, PA).

Figure 4 shows an illustration of the Markov process as a state-transition diagram. Each circle represents a Markov state. Allowed transitions are indicated by arrows connecting two different states. Arrows leading from a state to itself 
indicate that the patient may remain in that state in consecutive cycles. Only certain transitions are allowed. Patients in either of the Dead states cannot make a transition to any other state (for obvious reasons). It is assumed that a patient in a given state can make only a single state transition during a cycle.

The Markov-state diagram in Figure 4 lays out all of the possible paths that an individual patient may take (e.g. Well to Hip Fracture to Well to Dead, or Well to Hip Fracture to Well to Well). However, there is no way of knowing which paths are more or less likely. So, we calculate the net probability of making a transition from one state to another during a single cycle and assign this transition probability to each allowed transition. Once this was done, the entire Markov process is defined.

In order for a Markov process to terminate, it must have at least one state that a patient cannot leave called an absorbing state. In our model, like most medical examples, the absorbing states are the Death states. We have chosen to include two separate Death states in order to keep track of the cause of death.

\section{B The Markov-Cycle Tree}

Although a transition-state diagram like Figure 4 is useful when organizing a Markov process, it may be difficult to analyze. Instead, we convert the diagram to a Markov-cycle tree as shown in Figure 5.

Refer to Figure 4. From the Well state, it is possible to have a transition to the Hip Fracture state, the Dead from all causes state or back to the Well state. From the Hip Fracture state, transitions to either the Well state or the Dead from Hip Fracture state are possible. In our Markov-cycle tree, the transitions from a state are represented by the subtree emanating from that state. Notice that we can trace every transition shown in Figure 4 if we follow paths from the initial branches 
to the terminal nodes in Figure 5.

Initial state probabilities are entered below the initial Markov state branches. These are the probabilities of beginning the process in a particular state and must sum to 1.0. In our model, everyone begins in the Well state. Initial probabilities are used only once during the evaluation of a Markov model, to specify the initial distribution of the cohort at the beginning of stage 0 . All subsequent movement through the model utilizes transition probabilities, which will be specified under the branches to the right of the initial Markov states.

Tracker variables can be used to give a model memory during Monte Carlo simulation trials. In our model, we've used tracker variables to keep track of the number of hip and wrist fractures, to count the number of deaths from hip fracture, to keep track of the age at which hip fractures occur, and to force a choice at logic nodes. A list of the tracker variables used in the model along with their definition can be found in Table 3.

Our model employs two logic nodes. A logic node selects one path from its branches; rather than looking at expected values, it chooses a path by evaluating logical expressions. Each of its branches has an expression associated with it; starting at the top branch, the first node with an expression that evaluates to true is selected.

Markov state reward information is shown in Figure 8. Each states initial reward expression is evaluated only during stage 0 . It will be accumulated only by the portion of the cohort that is initially distributed to that state. The incremental reward is accrued by the membership of the state at each subsequent stage of the process, starting at stage 1 and continuing until the process terminates. In the final stage of the process, when the termination condition evaluates to true, the 


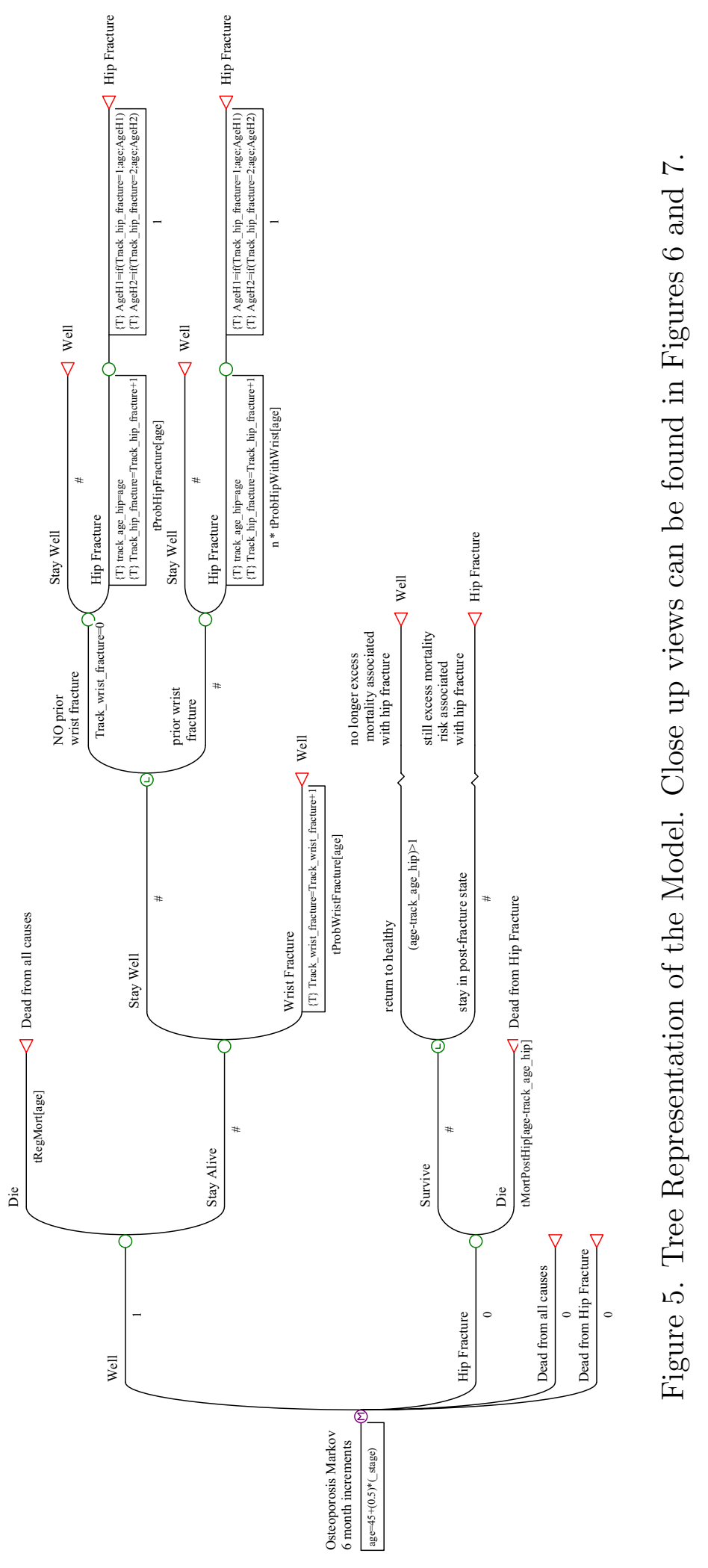




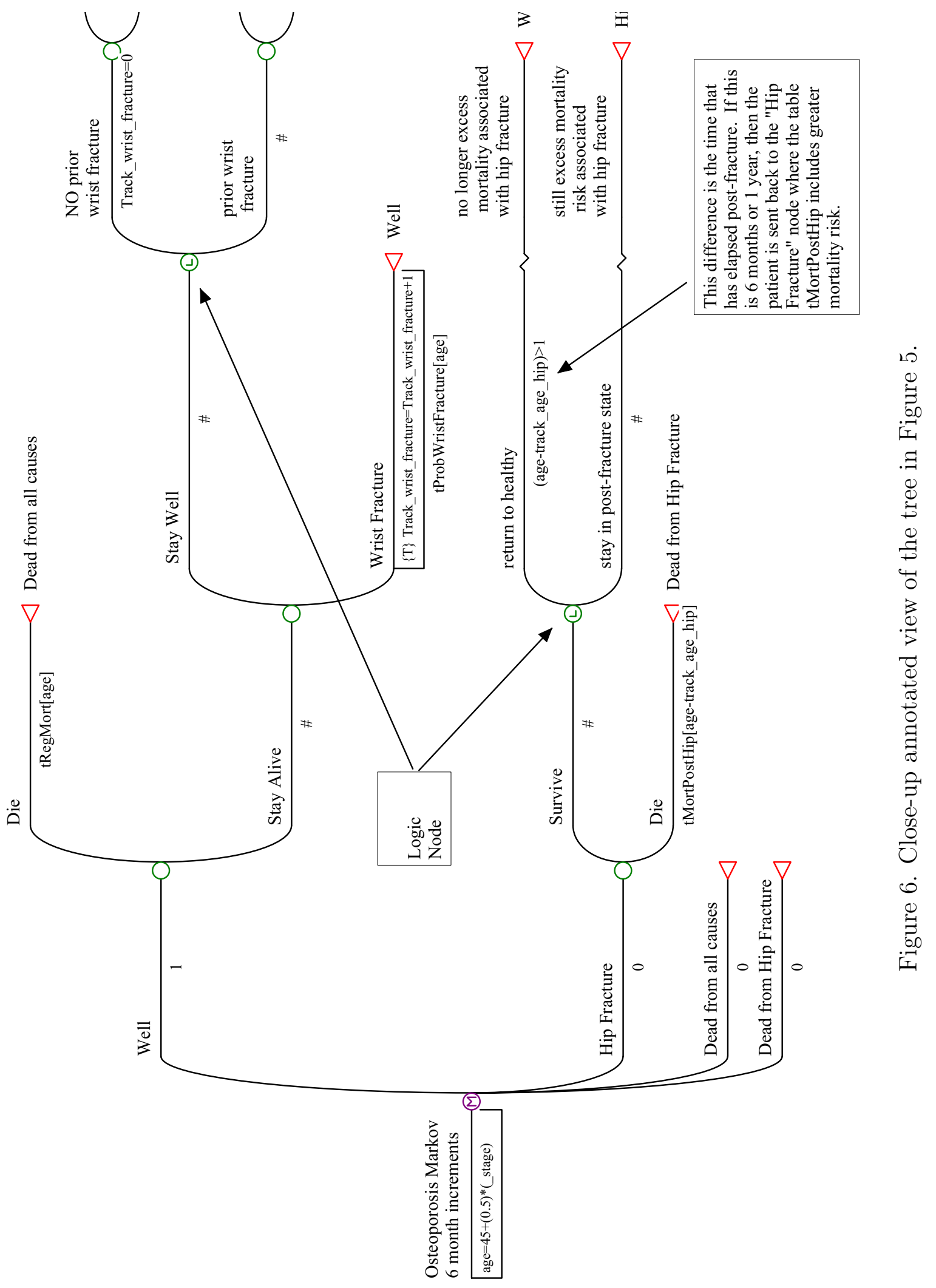




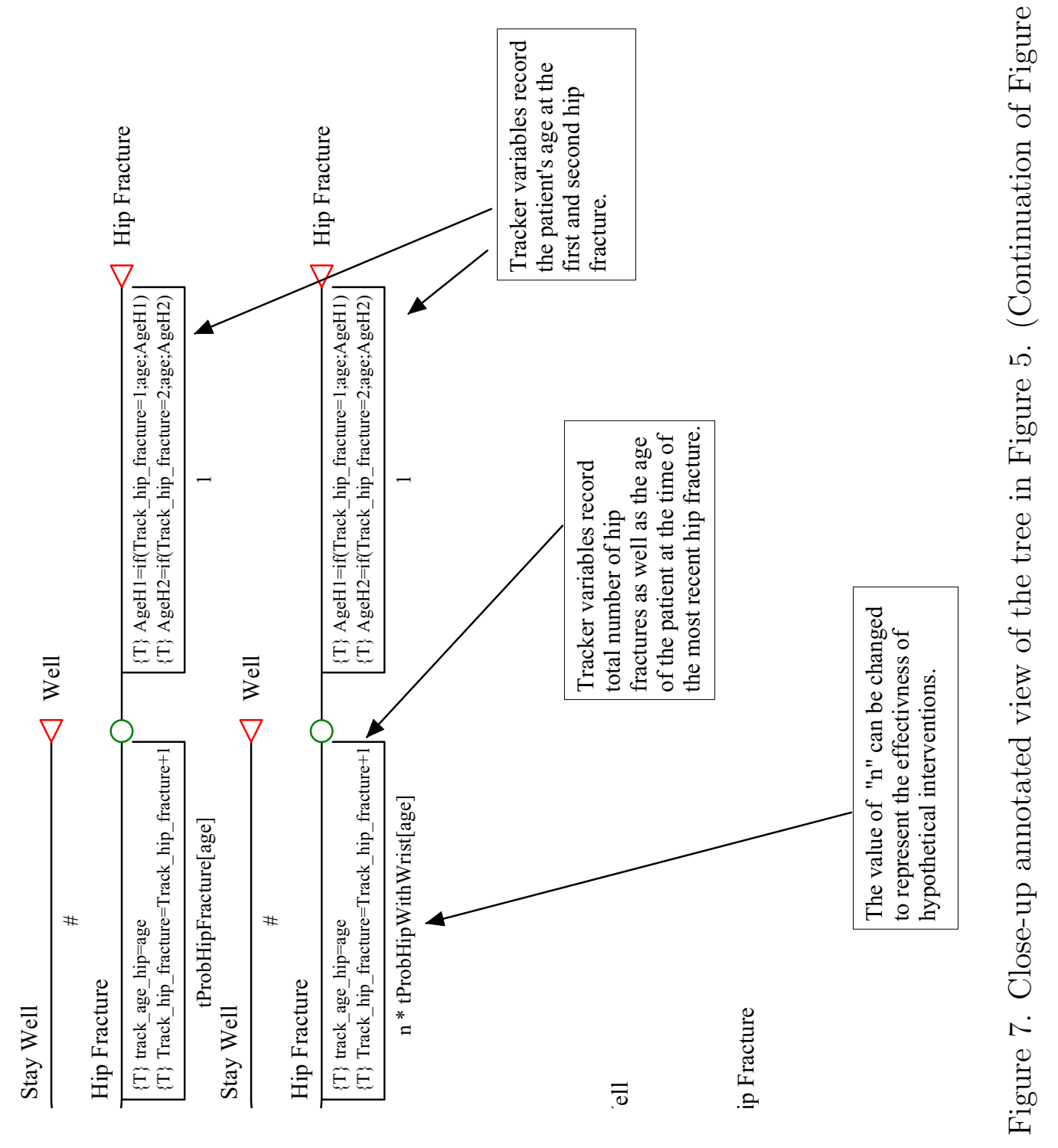


incremental state reward will not be accumulated, but the final reward will.

Since the entire cohort is initially distributed in the Well state, this is the only state with an initial reward. The incremental reward of 0.5 for the Well state and the Hip Fracture state gives a patient credit for each cycle spent in these two non-Dead states. The incremental reward is 0.5 since we have chosen a cycle length of 6 months. In effect, the incremental reward keeps track of how long the patient lives.

The initial reward for the Well state is 0.25 instead of 0.5. DATA suggests this half-cycle correction in order to improve Markov process approximations.

Real processes occur in continuous time, with transitions and other events occurring throughout an interval of time. In DATA, however, a Markov process occurs as a discrete sequence of snapshots, with transitions always occurring at the end of a stage. Without some kind of correction, the approximations inherent in discrete simulation of a real process can lead to significant errors in the calculation of average values in a cohort analysis, and individual values in Monte Carlo trials.

[User's Manual, DATA 4.0] 


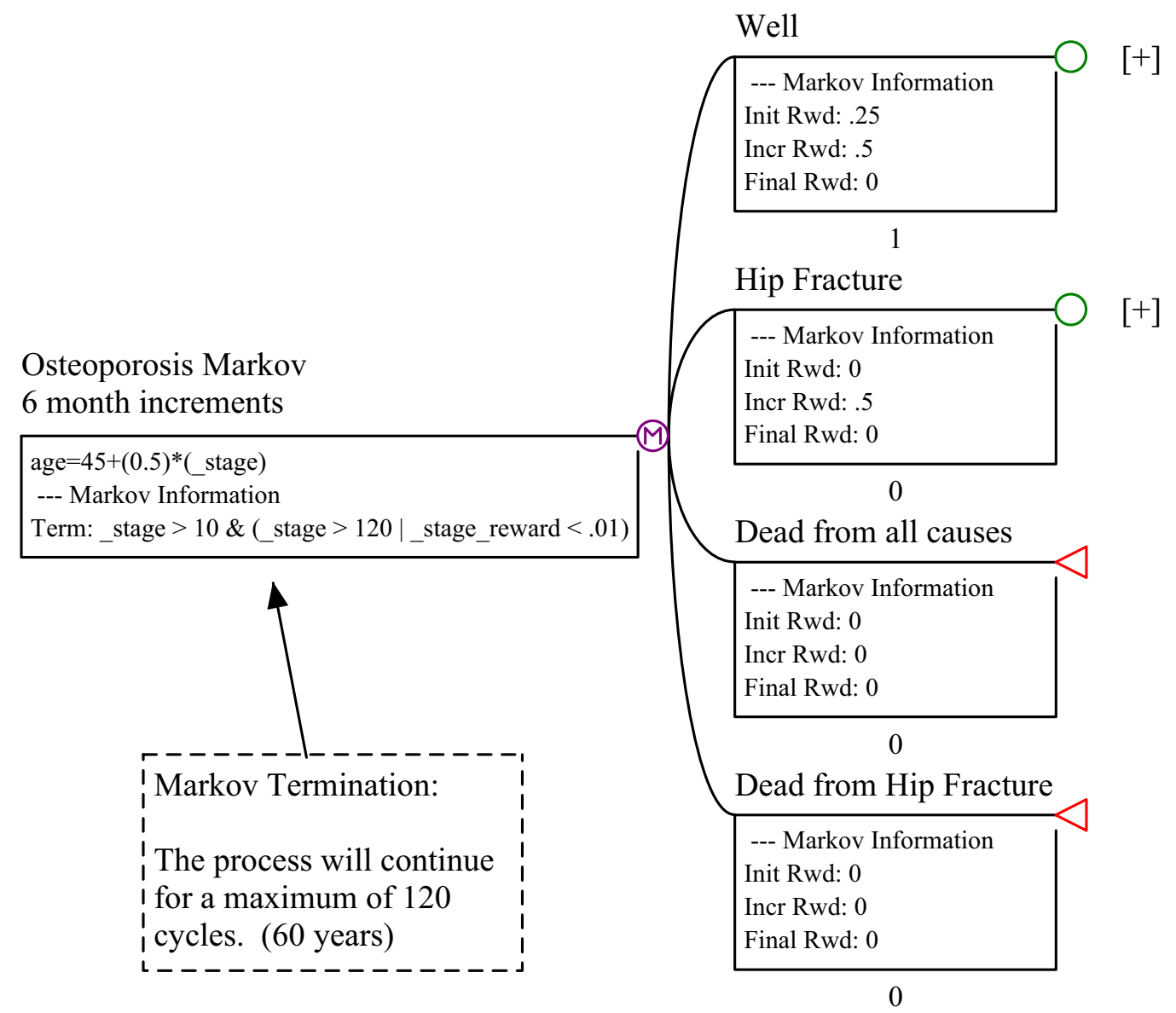

Figure 8. Markov state information. Note that a half-cycle correction has been used in the initial reward for the Well state. 


\section{Transition Probabilities}

At the beginning of our tree, we define a variable age. Since most fractures occur after age 45, we'll use this as our start age. As a patient completes a cycle in the model, they grow older. DATA automatically keeps track of the number of cycles that have been traversed in a variable called _stage. In our model, cycle length is 6 months, so we can imagine patients aging 6 months by the end of a cycle. So, at the beginning of every cycle, we'll compute age using the following formula:

$$
\text { age }=45+(0.5)(\text { _stage })
$$

For our transition probabilities, we created tables indexed by age. A list of all variables used in the model can be found in Section 2 .

The probabilities given in the literature for rates of hip fracture, wrist fracture and mortality are given in years. Our Markov-cycle duration is 6 months. We cannot simply divide the transition probabilities by 2 to arrive at the approximate transition probabilities for the shorter cycle. Instead we compute the bi-annual probabilities using the formula

$$
p=1-e^{-r / 2}
$$

where $r$ is the annual rate.

\section{Model Variables}


TABLE 3

Tracker variables used in the tree in Figure 5.

\begin{tabular}{l}
\multicolumn{2}{c|}{ Variable } \\
\begin{tabular}{|l|l|}
\hline$\{T\}$ AgeH1 & if(Track_hip_fracture=1;age;AgeH1) \\
\hline$\{T\}$ AgeH2 & if(Track_hip_fracture=2;age;AgeH2) \\
\hline$\{T\}$ track_age_hip & age \\
\hline$\{T\}$ Track_hip_fracture & Track_hip_fracture+1 \\
\hline$\{T\}$ Track_wrist_fracture & Track_wrist_fracture+1 \\
\hline$\{T\}$ dead_from_hip & dead_from_hip+1 \\
\hline
\end{tabular}
\end{tabular}

TABLE 4

Data compiled from tables found at the CDC web-site [41].

\section{National All Causes Mortality}

White, Non-Hispanic, Women by Age, 1997-2000

\begin{tabular}{r|c|c|c|c|c|} 
AGE: & $45-54$ & $55-64$ & $65-74$ & $75-84$ & $85+$ \\
\cline { 2 - 6 } MORTALITY: & 280.7 & 739 & 1911 & 4788.5 & 14798.2 \\
\cline { 2 - 5 } & \multicolumn{5}{c}{ Mortality (Rate p. 100,000) }
\end{tabular}


TABLE 5

tRegMort used in the model. (Bi-annual all-cause mortality rate). Converted from figures in Table 4 using Equation 2.

\begin{tabular}{|c|c|}
\multicolumn{1}{c}{ Age } & Mortality Rate \\
\hline $45-54$ & 0.002807 \\
\hline $55-64$ & 0.007390 \\
\hline $65-74$ & 0.019110 \\
\hline $75-84$ & 0.047885 \\
\hline $85+$ & 0.147982 \\
\hline
\end{tabular}


TABLE 6

tProbHipFracture used in the model. Hip fracture probabilities compiled from Lauritzen [12] and Kannus [40]. Converted to bi-annual probability using equation 2.

\begin{tabular}{|c|c|}
\multicolumn{1}{c}{ age } & $\begin{array}{c}\text { Probability of } \\
\text { Hip Fracture }\end{array}$ \\
\hline $45-49$ & 0.000454897 \\
\hline $50-54$ & 0.0020479 \\
\hline $55-59$ & 0.004539664 \\
\hline $60-64$ & 0.009009172 \\
\hline $65-69$ & 0.01916399 \\
\hline $70-74$ & 0.040026885 \\
\hline $75-79$ & 0.080982395 \\
\hline $80-84$ & 0.154815219 \\
\hline $85-89$ & 0.228292742 \\
\hline $90-94$ & 0.03165805 \\
\hline $95+$ & 0.037835649 \\
\hline
\end{tabular}


tProbWristFracture used in the model. Wrist fracture probabilities compiled from Lauritzen [12] and Kannus [40] were converted to bi-annual probability using equation 2 .

\begin{tabular}{|c|c|}
\multicolumn{1}{c}{ age } & $\begin{array}{c}\text { Probability of } \\
\text { Wrist Fracture }\end{array}$ \\
\hline $45-49$ & 0.001114379 \\
\hline $50-54$ & 0.001498876 \\
\hline $55-59$ & 0.002496878 \\
\hline $60-64$ & 0.004987521 \\
\hline $65-69$ & 0.007968085 \\
\hline $70-74$ & 0.0124222 \\
\hline $75-79$ & 0.018820638 \\
\hline $80-84$ & 0.018820638 \\
\hline $85-89$ & 0.018820638 \\
\hline $90-94$ & 0.020291304 \\
\hline $95+$ & 0.005494848 \\
\hline
\end{tabular}

TABLE 8

tMortPostHip used in the model. Mortality following hip fracture.

\begin{tabular}{|r|c|}
\multicolumn{1}{c|}{} & Probabilty of Death \\
\hline $0-6$ Months & 0.35 \\
\hline $6-12$ Months & 0.25 \\
\hline
\end{tabular}




\section{CHAPTER III}

\section{MONTE CARLO SIMULATION}

\section{A Analysis}

For our analysis, we modelled four separate hypothetical intervention strategies based on their level of effectiveness. The DATA 4.0 software offers two ways to evaluate a Markov model: Markov cohort simulation and Monte Carlo simulation. We chose to analyze our model using Monte Carlo simulation trials. In a single first-order trial of our Markov model, one member of a hypothetical cohort is randomly stepped through the process, based on the probabilities in the model. Our tracker variables helped us track each individual's particular steps through the process. This created a form of memory that we used in determining transitions. At the end of each cycle, a random-number generator was used together with the transition probabilities to determine in which state the patient would begin the next cycle. The patient is given credit for each cycle spent in a non-Dead state. Each trial generates a survival time. After a large number of trials, these constitute a distribution of the survival values. We can calculate the mean and standard deviation for this distribution.

We performed four separate Monte Carlo simulations consisting of 10,000 trials on our model in Figure 5. For each simulation, we changed the value of $n$ (See Figure 9) based on the effectiveness of our hypothetical intervention. The values 


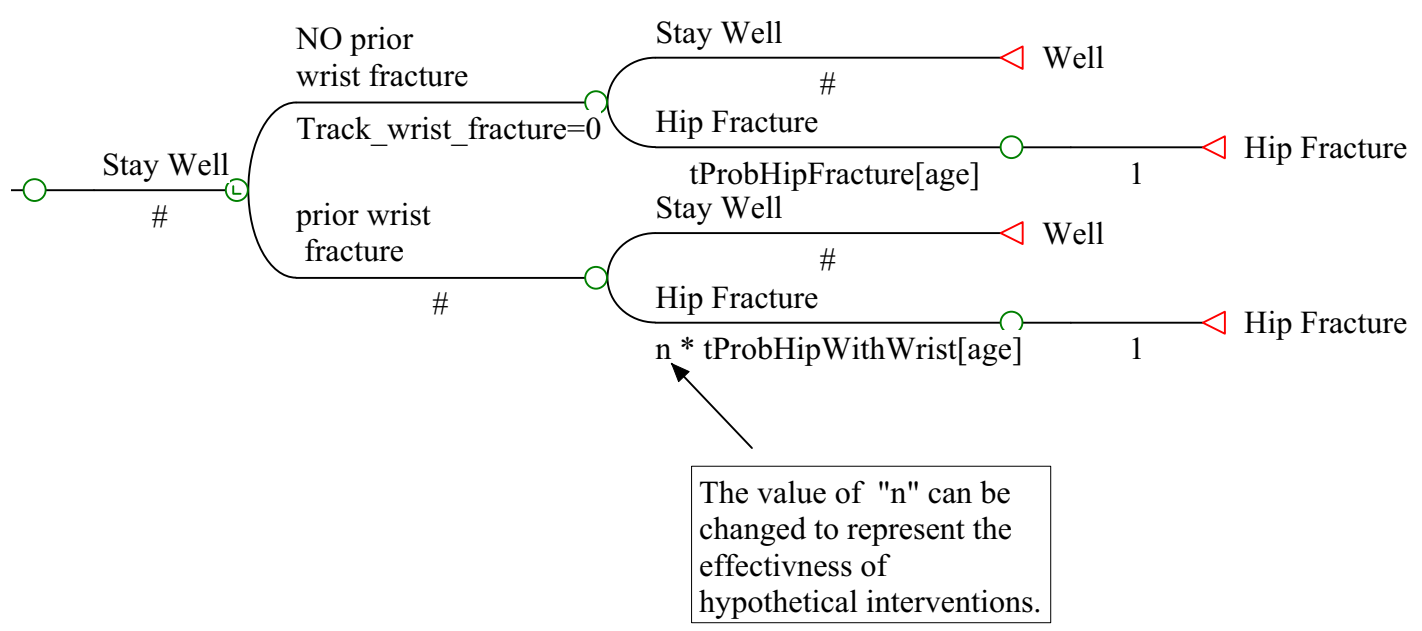

Figure 9. Four Monte Carlo simulations were run, each using one of the values for $n$ found in Table 9

used are summarized in Table 9.

A wrist fracture imparts an approximate 2-fold increase in the risk of a subsequent hip fracture $[12,11]$. Our hypothetical interventions model the effect of reducing this increase by increments of 0.5 . 
TABLE 9

These values were substituted into the model and four separate Monte Carlo simulations were performed. (Refer to Figures 5 and 9).

Value of $n$

\begin{tabular}{|c|c|}
\hline No Intervention & 2.0 \\
\hline Moderate Intervention & 1.5 \\
\hline Effective Intervention & 1.0 \\
\hline Highly Effective Intervention & 0.5 \\
\hline
\end{tabular}

\section{B Results}

The mean survival for each of the four intervention groups is given in Table 10. An intervention that decreases the risk of a hip fracture after a wrist fracture from 2 to $1.5,1.0$, or 0.5 can increase life expectancy by $0.271,0.557$, or 1.049 years, respectively.

The number of patients that experienced zero fractures was 190 greater in the Effective Intervention group and 490 greater in the Highly Effective Intervention group (Table 11). Of patients who did experience fractures, there were between 140 and 240 fewer patients who experienced a second fracture in the intervention groups compared to the no-intervention group (Table 12).

Tables 13 and 14 illustrate that interventions can delay the occurrence of a first or second hip fracture following a wrist fracture. 
TABLE 10

Comparison of expected survival (in years) for the four groups.

\begin{tabular}{r|c|c|c|c|}
\multicolumn{1}{c}{} & \multicolumn{1}{c}{$\begin{array}{c}\text { No } \\
\text { Intervention }\end{array}$} & \multicolumn{1}{c}{$\begin{array}{c}\text { Moderate } \\
\text { Intervention }\end{array}$} & \multicolumn{1}{c}{$\begin{array}{c}\text { Effective } \\
\text { Intervention }\end{array}$} & $\begin{array}{c}\text { Highly Effective } \\
\text { Intervention }\end{array}$ \\
\cline { 2 - 5 } Mean & 27.846 & 28.117 & 28.403 & 28.895 \\
\cline { 2 - 5 } Std Dev & 9.217 & 9.278 & 9.682 & 9.921 \\
\cline { 2 - 5 } Effect of Intervention & & 0.271 & 0.557 & 1.049 \\
\cline { 2 - 5 } & & & &
\end{tabular}

TABLE 11

Results of Monte Carlo Simulations. Number of patients (out of 10,000) who experienced zero hip fractures.

\begin{tabular}{r|c|c|}
\multicolumn{1}{c}{} & \multicolumn{1}{c}{$\begin{array}{c}\text { Number of } \\
\text { Patients }\end{array}$} & $\begin{array}{c}\text { Difference Due } \\
\text { to Intervention }\end{array}$ \\
\cline { 2 - 3 } No Intervention & 2590 & \\
\cline { 2 - 3 } Moderate Intervention & 2600 & 10 \\
\cline { 2 - 3 } Effective Intervention & 2780 & 190 \\
\cline { 2 - 3 } Highly Effective Intervention & 3080 & 490 \\
\cline { 2 - 3 }
\end{tabular}


TABLE 12

Results of Monte Carlo simulations. Number of patients (out of 10,000) who experienced a second hip fracture.

\begin{tabular}{r|c|c|}
\multicolumn{1}{c}{} & \multicolumn{1}{c}{$\begin{array}{c}\text { Number of } \\
\text { Patients }\end{array}$} & $\begin{array}{c}\text { Difference Due } \\
\text { to Intervention }\end{array}$ \\
\cline { 2 - 3 } No Intervention & 1590 & \\
\cline { 2 - 3 } Moderate Intervention & 1450 & -140 \\
\cline { 2 - 3 } Effective Intervention & 1410 & -180 \\
\cline { 2 - 3 } Highly Effective Intervention & 1350 & -240 \\
\cline { 2 - 3 } & &
\end{tabular}

TABLE 13

Results of Monte Carlo simulations. Distribution of age at time of first hip fracture.

\begin{tabular}{|c|c|c|c|c|}
\hline & $\begin{array}{c}\text { No } \\
\text { Intervention } \\
\end{array}$ & $\begin{array}{c}\text { Moderate } \\
\text { Intervention }\end{array}$ & $\begin{array}{c}\text { Effective } \\
\text { Intervention }\end{array}$ & $\begin{array}{l}\text { Highly Effective } \\
\text { Intervention }\end{array}$ \\
\hline $45-49$ & 0.005 & 0.005 & 0.005 & 0.004 \\
\hline $50-54$ & 0.021 & 0.021 & 0.022 & 0.021 \\
\hline $55-59$ & 0.042 & 0.043 & 0.041 & 0.04 \\
\hline $60-64$ & 0.08 & 0.072 & 0.068 & 0.072 \\
\hline $65-69$ & 0.144 & 0.136 & 0.125 & 0.119 \\
\hline $70-74$ & 0.194 & 0.193 & 0.181 & 0.166 \\
\hline $75-79$ & 0.178 & 0.185 & 0.179 & 0.159 \\
\hline $80-84$ & 0.067 & 0.076 & 0.089 & 0.087 \\
\hline $85-89$ & 0.009 & 0.01 & 0.012 & 0.021 \\
\hline $90-94$ & 0 & 0 & 0 & 0.001 \\
\hline $95-99$ & 0 & 0 & 0 & 0.001 \\
\hline
\end{tabular}


TABLE 14

Results of Monte Carlo simulations. Distribution of age at time of second hip fracture.

\begin{tabular}{|c|c|c|c|c|}
\hline & $\begin{array}{c}\text { No } \\
\text { Intervention }\end{array}$ & $\begin{array}{c}\text { Moderate } \\
\text { Intervention }\end{array}$ & $\begin{array}{c}\text { Effective } \\
\text { Intervention }\end{array}$ & $\begin{array}{l}\text { Highly Effective } \\
\text { Intervention }\end{array}$ \\
\hline $45-49$ & 0 & 0 & 0 & 0 \\
\hline $50-54$ & 0 & 0 & 0 & 0 \\
\hline $55-59$ & 0.001 & 0.001 & 0.001 & 0 \\
\hline $60-64$ & 0.004 & 0.002 & 0.003 & 0.002 \\
\hline 65-69 & 0.011 & 0.009 & 0.008 & 0.008 \\
\hline $70-74$ & 0.038 & 0.034 & 0.028 & 0.025 \\
\hline $75-79$ & 0.081 & 0.072 & 0.062 & 0.056 \\
\hline $80-84$ & 0.074 & 0.072 & 0.075 & 0.06 \\
\hline $85-89$ & 0.019 & 0.021 & 0.026 & 0.027 \\
\hline $90-94$ & 0 & 0 & 0.001 & 0.001 \\
\hline $95-99$ & 0 & 0 & 0 & 0.001 \\
\hline
\end{tabular}




\section{Discussion}

The results of this analysis show that if all patients that present with a wrist fracture are treated with an successful intervention, then it is possible to increase survival in post-menopausal white women. Even for a moderate intervention, we can gain up to 3 months average survival. This is encouraging, given the number of women at risk of sustaining a hip fracture following a fracture of the distal radius. A gain of up to one year of life for highly effective interventions shows that an exploration of aggressive therapies is worthwhile.

Our analysis has shown that if an Effective treatment is targeted toward a sample of 10,000 women, then we can prevent up to 190 post-wrist hip fractures. For a Highly Effective treatment, this number rises to 490.

The number of avoided hip fractures is important in light of a recent study by Braithwaite, et. al. in 2003, where the lifetime attributable cost of hip fracture was calculated to be $\$ 81,300$ [42]. Table 15 contains a simple cost analysis. From these figures, it seems reasonable to assume that cost-effective interventions are possible.

\section{Suggestions For Further Research}

Our primary aim in this research was to find the amount of life that could be gained and the number of fractures that could be avoided. It is our opinion that these numbers suggest that future research is warranted.

We have developed a model that estimates years of survival. Although this is important, it does not capture the complexity of the entire hip fracture problem. Hip fractures incur tremendous morbidity. So, by preventing a hip fracture, we not only prolong a patient's life, but also sustain that patient's quality of life. 


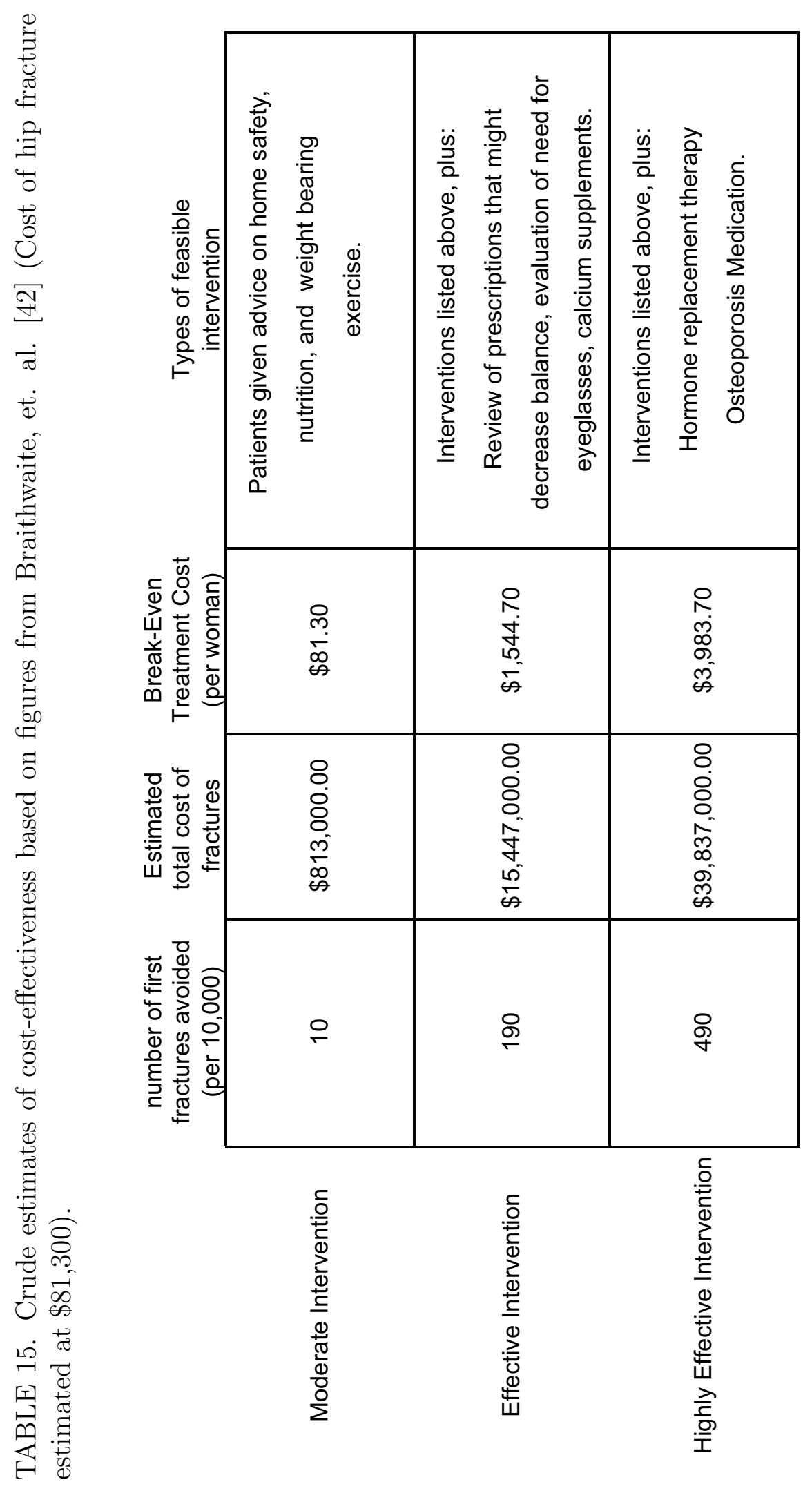


A future study that examines the quality of life related to osteoporotic fracture could compute Quality Adjusted Life Years (QALY's) that are comparable among various diseases.

Formal decision analysis could be used to determine the most useful interventions. Cost-effectiveness analysis could determine if we could develop interventions that are worthwhile. 


\section{CHAPTER IV}

\section{CONCLUSION}

Physicians often regard fractures of the spine, wrist, and hip as quintessential osteoporotic fractures [39]. However, it is often the case that even when women present with these fractures, they remain undiagnosed for osteoporosis and therefore many are not treated. Since a significant proportion of osteoporotic fractures occur in peri-menopausal women with substantial life expectancy, secondary prevention is important [43].

Osteoporotic fractures are associated with higher health care costs, physical disability, impaired quality of life, and increased mortality. Because the incidence of osteoporotic fracture increases with advancing age, measures to diagnose and prevent osteoporosis and its complications assume a major public health concern [5].

The vast majority of men and women at risk for osteoporosis never visit specialists, and the relatively small numbers who do, do so when the disease process is advanced-generally after at least one fracture has occurred or bone is seriously compromised, after many years of asymptomatic bone loss. Because of the long preclinical period, there is ample opportunity for intervention early in the course of disease [17].

Our research has shown that if patients with prior wrist fractures could be targeted with an intervention, then it is possible to reduce the number of subsequent hip fractures and increase survival in postmenopausal white women. 


\section{REFERENCES}

[1] Kannus P, Niemi S, Parkkari J, et al. Why is the age-standardized incidence of low-trauma fractures rising in many elderly populations? J Bone Miner Res. $2002 ; 17: 1363-1367$.

[2] Ross PD. Osteoporosis: Frequency, consequences, and risk factors. Arch Intern Med. 1996;156:1399-1411.

[3] "Osteoporosis," Microsoft Encarta Online Encyclopedia. 2003. Available at: http://encarta.msn.com 1997-2003 Microsoft Corporation. All Rights Reserved. Accessed December 14, 2003.

[4] Theodorou SJ, Theodorou DJ, Satoris DJ. Evaluation of osteoporosis in orthopedic practice: a review of current diagnostic modalities. Am J Orthop. 2003;32:178-188.

[5] Srivastava M, Deal C. Osteoporosis in elderly: prevention and treatment. Clin Geriatr Med. 2002;18:529-555.

[6] Stephen AB, Wallace WA. The management of osteoporosis J Bone Joint Surg Br. 2001;83-B:316-23.

[7] Phillips CJ, Moore RA. Developing a strategy for the prevention of hip fractures in the elderly due to osteoporosis: the application of economics to the findings from a clinical trial. IJCP. 1998;52:335-340. 
[8] Mueller G, Russell RGG. Osteoporosis: pathogenesis and clinical intervention. Biochem Soc Trans. 2003;31:462-464.

[9] Oslchewski E, Murray P, Buckley R, Fennell C, Powell JN. Assessment of osteoporosis using standard radiographs of the wrist. J Trauma. 2001;15:912-916.

[10] Ray NF, Chan JK, Thamer M, Melton LJ III. Medical expenditures for the treatment of osteoporotic fractures in the United States in 1995: report from the national osteoporosis foundation. J Bone Miner Res. 1997;12:24-35.

[11] Martens MG. Risk of fracture and treatment to prevent osteoporosis-related fracture in postmenopausal women: A review. J Reprod Med. 2003;48:425-434.

[12] Lauritzen JB, Schwarz P, Mcnair P, Lund B, Transbol I. Radial and humeral fractures as predictors of subsequent hip, radial or humeral fractures in women, and their seasonal variation. Osteoporos Int. 1993;3:133-137.

[13] Chrischilles E, Shireman T, Wallace R. Costs and health effects of osteoporotic fractures. Bone. 1994;15:377-386.

[14] Screening for osteoporosis in postmenopausal women: recommendations and rationale. Am J Nurs. 2003;103:73-80.

[15] Theodorou SJ, Theodorou DJ, Satoris DJ. Osteoporosis and fractures: the size of the problem. Hosp Med. 2003;64:87-92.

[16] Walker-Bone K, Walter G, Cooper C. Recent developments in the epidemiology of osteoporosis. Curr Opin Rheumatol. 2002;14:411-415. 
[17] Wehren LE. The role of the primary care physician in diagnosis and management of osteoporosis. Int J Fertil. 2002;47:116-122.

[18] Cummings SR, Melton LJ III. Epidemiology and outcomes of osteoporotic fractures. Lancet. 2002;359:1761-1767.

[19] Brunelli M, Einhorn T. Medical management of osteoporosis: fracture prevention. Clin Orthop. 1998;348:15-21.

[20] Vogt MT, Cauley JA, Tomaino MM, Stone K, Williams JR, Herndon JH. Distal radius fractures in older women: a 10-year follow-up study of descriptive characteristics and risk factors. The study of osteoporotic fractures. $J$ Am Geriatr Soc. 2001;50:97-103.

[21] Eastell R, Reid DM, Compston J, et al. Secondary prevention of osteoporosis: when should non-vertebral fracture be a trigger for action? QJM. 2001;94:575-597.

[22] Keen RW, Griffiths GO, Spector TD. Patients who have had fractures of the distal forearm do not lose bone as expected. BMJ. 1996;313:821.

[23] Rozental TD, Branas CC, Bozentka DJ, Beredjiklian PK. Survival among elderly patients after fractures of the distal radius. J Hand Surg. 2002;27A:948-952.

[24] MEDLINEplus Medical Encyclopedia: Hip Fracture. 2003. Available at: http://www.nlm.nih.gov/medlineplus/ency/imagepages/18026.htm. Accessed December 14, 2003 . 
[25] Robinson JM, Royds M, Abraham A, McQueen MM, Court-Brown CM, Christie J. Refractures in patients at least forty-five years old: A prospective analysis of twenty-two thousand and sixty patients. JBJS. 2002;84-A:1528-1533.

[26] Richmond J, GB Aharanoff, Zuckermank JD, Koval KJ. Mortality Risk After Hip Fracture J Orthop Trauma. 2003;17:53-56.

[27] Mellinger E. Identifying risk factors for and preventing hip fractures in elderly patients. AORN. 1997;66:688-693.

[28] Magaziner J, Lydick E, Hawkes W, et al. Excess mortality attributable to hip fracture in white women aged 70 years and older. Am J Public Health. $1997 ; 87: 1630-1636$.

[29] Salkeld G, Cameron ID, Cumming RG, et al. Quality of life related to fear of falling and hip fracture in older women: a time trade off study. BMJ. 2000;320:341-346.

[30] Stewart A, Calder LD, Torgerson DJ, et al. Prevalence of hip fracture risk factors in women aged 70 years and over. QJM. 2000;93:677-680.

[31] Cadarette SM, Jaglal SB, Murray TM, McIsaac WJ, Joseph L, Brown JP. Evaluation of decision rules for referring women for bone densitometry by dual-energy X-ray absorptiometry. JAMA. 2001;286:57-63.

[32] Siris ES, Miller PD, Barrett-connor E, et al. Identification and fracture outcomes of undiagnosed low bone mineral density in postmenopausal women: results from the national osteoporosis risk assessment. JAMA. $2001 ; 286: 2815-2822$. 
[33] Mallmin H, Ljunghall S, Persson I, Naessén T, Krusemo U-A, Bergström R. Fracture of the distal forearm as a forecaster of subsequent hip fracture: A population-based cohort study with 24 years of follow-up. Calcif Tissue Int. 1993;S2:269-272.

[34] Cuddihy MT, Gabriel SE, Crowson CS, O’Fallon WM, Melton LJ III. Forearm fractures as predictors of subsequent osteoporotic fractures. Osteoporos Int. 1999;9:469-475.

[35] Simonelli C, Killeen K, Mehle S, Swanson L. Barriers to osteoporosis identification and treatment among primary care physicians and orthopedic surgeons. Mayo Clin Proc. 2002;77:337-338.

[36] Gunnes M, Mellstrom D, Johnell O. How well can a previous fracture indicate a new fracture? A questionnaire study of 29,802 postmonopausal women. Acta Orthop Scand. 1998;69:508-512.

[37] Solomon DH, Finkelstein JS, Katz JN, Mogun H, Avorn J. Underuse of osteoporosis medications in elderly patients with fractures. Am J Med. 2003;115:398-400.

[38] Cuddihy M, Gabriel SE, Crowson CS, et al. Osteoporosis intervention following distal forearm fractures: A Missed Opportunity? Arch Intern Med. $2002 ; 162: 421-426$.

[39] Cummings SR, Black DM, Nevitt MC, et al. Bone density at various sites for prediction of hip fractures. Lancet. 1993;341:72-75.

[40] Kannus P, Parkkari J, Niemi S, et al. Prevention of hip fracture in elderly people with the use of a hip protector. $N$ Engl J Med. 2000;343:1506-1513. 
[41] Centers for Disease Control and Prevention. National Center for Health Statistics. Healthy Women: State Trends in Health and Mortality. Available at: http://www.cdc.gov/nchs/healthywomen.htm. Accessed November 3, 2003 .

[42] Braithwaite RS, Col NF, Wong JB. Estimating hip fracture morbidity, mortality and costs. J Am Geriatr Soc. 2003;51:364-370.

[43] George GHM, Patel S. Secondary prevention of hip fracture. Rheumatology. 2000;39:346-349. 


\section{CURRICULUM VITAE}

NAME: $\quad$ Stephanie Tapp

ADDRESS: Department of Bioinformatics and Biostatistics

University of Louisville

Louisville, KY 40292

EDUCATION: $\quad$ B.A. Mathematics

University of Louisville

1997

TEACHING: Graduate Teaching Assistant

Department of Mathematics 1998-2000

University of Louisville 